\section{El curso sobre intervención en patrimonio contemporáneo se plantea futuras ediciones}

Las cuestiones relativas a la conservación y la intervención en el patrimonio arquitectónico contemporáneo constituyen un reto a resolver, por tratarse de un campo hasta ahora relativamente inexplorado. En ese marco se produjo la celebración conjunta, por parte del Instituto Andaluz del Patrimonio Histórico y de la Fundación Docomomo Ibérico, del curso "Intervenir en el patrimonio contemporáneo. Métodos y Técnicas", en la sede del IAPH en noviembre de 2009. Los participantes insistieron en la necesidad de elaborar un corpus teórico de intervención en este patrimonio, que incorpore los requerimientos procedentes de nuevas normativas.

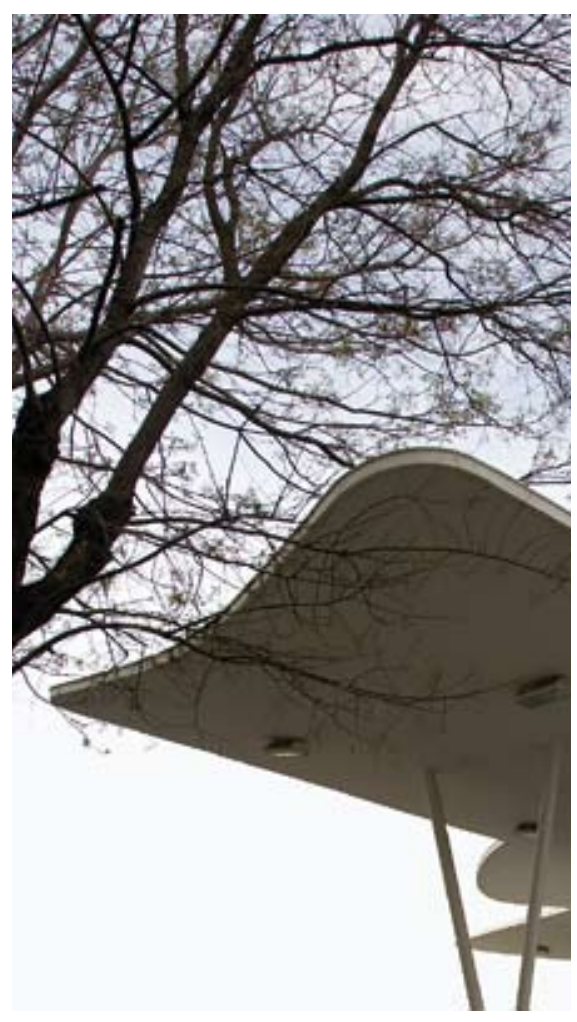

Imagen del cartel del curso. Estación de servicio en Huelva (1956), obra de Alejandro Herrero Ayllón. Foło: Julia Manzano Pérez de Guzmán

Desde que Joseph Asdyn consiguiese en 1826 la patente del cemento Portland, la evolución de la apreciación del comportamiento de materiales propios de la modernidad como el hormigón armado, el acero y el vidrio ha experimentado un cambio $\int$ radical. Desde la imaginación de su inmunidad al paso del tiempo, hasta su homologación a otros materiales "tradicionales", el envejecimiento de los elementos que constituian la encarnadura de la arquitectura contemporánea se ha convertido en objeto de estudio, en un campo hasta ahora relativamente inexplorado en el que se inscribe el curso.

Con una duración de 20 horas, el curso respondió durante los dias 18, 19 y 20 de noviembre de 2009 a la necesidad de un marco general de reflexión, donde las intervenciones de especialistas como Martín Capeluto, de la Universidad Politécnica de Cataluña, y Ascensión Hernández, de la Universidad de Zaragoza, han incidido en los aspectos relativos a la autenticidad y la materialidad de una arquitectura que, siendo partícipe del espíritu de los tiempos, se propuso superar los tradicionales valores de estabilidad y firmeza.

Esta visión teórica se ha complementado con un acercamiento a la problemática específica del hormigón armado, cuya caracterización corrió a cargo de los investigadores del Instituto Eduardo Torroja, José Pedro Gutiérrez y David Revuelta, quienes presentaron la experiencia en la intervención en edificios singulares, como el Mercado de Abastos de Algeciras, las naves Boetticher en Madrid y la Lonja de Pescado de Barbate. Similar aproximación científica al tema del hormigón fue aportada por Osvaldo Otero, investigador del Laboratorio de Entrenamiento Multidisciplinario para la Investigación Tecnológica (LEMIT) de Argentina, expuso la casuistica del uso de hormigones superfludificantes para la recuperación de la obra del arquitecto Francisco Salamone en la Provincia de Buenos Aires.

La aproximación al hormigón armado puso de relevancia la importancia de la documentación para avanzar en el conocimiento de técnicas y normativas del momento. En ese sentido, la intervención de Ana Tostões, presidenta de Docomomo Internacional, estuvo orientada a describir la especificidad material e ideológica de la arquitectura del Movimiento Moderno, así como a exponer la envergadura de la acción de Docomomo, especialmente en la actuación del Comité Internacional de Expertos en Tecnología y en la publicación periódica de los Docomomo Proceedings.

Esta intervención dio paso a los casos de estudio del Coliseo de Lisboa y el Liceo de Beja, ambas obras del arquitecto portugués Cristino da Silva, que fueron expuestos por los arquitectos encargados de su rehabilitación, respectivamente, Alberto Souza Oliveira y Pedro Viana Botelho. Estas presentaciones culminaron con la intervención de Wessel de Jonge, fundador de la organización Docomomo, quien expuso las experiencias del sanatorio Zonenstraal y la Fábrica Van Nelle, en Holanda, haciendo énfasis en el reto que supuso el tratamiento de los elementos de carpinterías metálicas y del vidrio, de una manera ejemplar.

Las conclusiones, expuestas en la mesa redonda con la que se cerró el curso, estuvieron centradas en la necesidad de la elaboración de un corpus teórico que plantee de manera sistemática la intervención en este patrimonio, y que de manera específica, integre los nuevos requerimientos procedentes de nuevas normativas. Es por ello, que tras el éxito de la presente edición, se trabaje actualmente en la continuidad futura de estas actividades.

Plácido González Martínez

Centro de Documentación y Estudios Instituto Andaluz del Patrimonio Histórico 